\title{
Congenital muscular dystrophy: brain alterations in an unselected series of Western patients
}

\author{
C P Trevisan, C Carollo, P Segalla, C Angelini, P Drigo, R Giordano
}

\begin{abstract}
The typical form of congenital muscular dystrophy (CMD) described in Western countries is generally considered different from its Japanese variant because of the absence of CNS involvement. Evaluations from both a clinical and a neuroradiological point of view were made of the CNS functions of 12 unselected Western children affected by CMD. In five patients, clinical observation and intelligence tests showed a mild to severe mental retardation. One of these patients suffered also from a severe form of epilepsy. In the same five patients, various degrees of white matter hypodensity, ventricular enlargement and cerebral atrophy were also detected. Similar neuroradiological abnormalities were also found in five of the seven children who did not have clinical symptoms or signs of CNS involvement. In one of these cases, necropsy neuropathological examination showed the gyral anomalies characteristic of the Japanese type of CMD. This study clearly indicates the high frequency of subclinical CNS alterations in typical Western CMD, suggesting that it should be considered a type of myoencephalopathy like its Japanese counterpart.
\end{abstract}

Diagnostic features of congenital muscular dystrophy (CMD) are represented by a neonatal muscular deficit with evidence of dystrophic alterations at muscle biopsy. ${ }^{1-5}$ The term "congenital muscular dystrophy" was first used by Howard in $1908,{ }^{6}$ but according to Nonaka and $\mathrm{Chou}^{2}$ reliable cases of CMD were not described before 1940 .

CMD has usually been distinguished in different forms on a clinical-pathological ground. The Japanese variant reported by Fukuyama et al in $1960^{7}$ differs from the typical form described in Western countries because of the presence of central nervous system (CNS) alterations. ${ }^{1-58-10}$ However, brain involvement has occasionally been reported also in non-Japanese children affected by CMD. ${ }^{11-29}$ To establish the frequency of these alterations in typical CMD, we considered an unselected series of 12 Western children affected by this myopathy: in all of them CNS conditions were investigated from both a clinical and a radiological point of view. In one case, a necropsy neuropathological examination was also performed.

\section{Cases}

In this study we considered 12 patients, four males and eight females, with a mean age of seven years and eight months (table 1). Onset was neonatal in all cases. They were all of white ancestry and represented the unselected series of the CMD cases diagnosed between 1981-86 at the Neuromuscular Centre, University of Padua, Italy. This centre serves the central and eastern Veneto provinces, to which all patients with neuromuscular disorders are referred for muscle biopsy. The diagnostic criteria were: the presence of muscular hypotonia with a varying degree of weakness from the neonatal period, and a muscle biopsy showing clear pathological changes of dystrophic type (such as, marked variation in fibre size, necrotic and regenerated fibres, phagocytosis and fibrosis). Muscle biopsy was not performed in cases 7 and 10 because it had already been diagnosed in their sisters, cases 6 and 9 respectively. Family history was positive in four patients: cases 6 and 7 were identical twins, while case 9 was the older sister of case 10 . At birth, a variable extension of arthrogryposis multiplex was observed in seven cases (see table 1). Six patients (cases $3,4,5,9,10,12$ ) eventually developed the ability to walk and to climb stairs, whereas the others (cases $1,2,6,7,8$, 11) were only able to sit. The muscular deficit showed a continuous clinical improvement in six children (cases 3, 4, 5, 9, 10, 12), whereas in the others no major variations of the muscular functions were observed over a period of years (cases $1,2,6,7,8,11$ ). The only patient who died was case 8 : his death was caused by an epidural haematoma following an accidental head trauma, when he was six years old.

At the time of our CNS investigation, the muscular functions of our patients were as reported in table 1 . Plasma CPK was variably increased, ranging from 2 (case 12) to 25 times (case 10) the highest normal value. Electromyography showed myopathic alterations in all cases.

\section{CNS evaluation}

Each patient had a complete neurological and psychiatric examination. Their intellectual ability was evaluated by clinical observation and by the Stanford-Binet Intelligence Scale (Italian revision) or Raven Progressive Matrices. Some cases were also given the Italian revision of the Wechsler Intelligence Scale for Children (WISC) or Wechsler Preschool and Primary Scale of Intelligence. Routine electroencephalography (EEG) was 
Table 1 Clinical data of the 12 patients with $C M D$

\begin{tabular}{|c|c|c|c|c|c|c|c|c|c|c|c|c|}
\hline $\begin{array}{l}\text { Case } \\
\text { Age (years, months) } \\
\text { Sex }\end{array}$ & $\begin{array}{l}1 \\
16 \cdot 3 \\
M\end{array}$ & $\begin{array}{l}2 \\
\mathrm{~F} \cdot 10\end{array}$ & $\begin{array}{l}3 \\
10 \cdot 8 \\
F\end{array}$ & $\begin{array}{l}4 \\
11 \cdot 8 \\
F\end{array}$ & $\stackrel{5}{9}^{9}$ & $\stackrel{6}{6}_{\mathrm{F}}$ & $\begin{array}{l}7 \\
6 \cdot 2\end{array}$ & $\stackrel{8}{6 \cdot 0}$ & $\begin{array}{l}9 \\
6 \cdot 4 \\
F\end{array}$ & $\begin{array}{l}10 \\
2 \cdot 7 \\
\mathrm{~F}\end{array}$ & $\begin{array}{l}11 \\
M \cdot 4\end{array}$ & $\begin{array}{l}12 \\
\mathbf{6} \cdot 7\end{array}$ \\
\hline Positive family history & - & - & - & - & - & + & + & - & + & + & - & - \\
\hline $\begin{array}{l}\text { Congenital arthrogryposis } \\
\text { Motor milestones }\end{array}$ & 8 & 2 & 4 & 2 & - & 2 & 2 & 6 & - & - & - & - \\
\hline $\begin{array}{l}\text { head control } \\
\text { sitting }\end{array}$ & $\begin{array}{l} \pm(5 \mathrm{mo}) \\
\pm(10 \mathrm{mo})\end{array}$ & $\begin{array}{l} \pm(6 \mathrm{mo}) \\
\pm(14 \mathrm{mo})\end{array}$ & $\begin{array}{l}+(6 \mathrm{mo}) \\
+(15 \mathrm{mo})\end{array}$ & $\begin{array}{l}+(4 \mathrm{mo}) \\
+(10 \mathrm{mo})\end{array}$ & $\begin{array}{l}+(5 \mathrm{mo}) \\
+(2 \mathrm{yr})\end{array}$ & $\begin{array}{l}+(3 \mathrm{yr}) \\
+(4 \mathrm{yr})\end{array}$ & $\begin{array}{l}+(2 \mathrm{yr}) \\
+(3 \mathrm{yr}) \pm\end{array}$ & $\pm \begin{array}{r}(6 \mathrm{mo}) \\
(14 \mathrm{mo})\end{array}$ & $\begin{array}{l}+(5 \mathrm{mo}) \\
+(13 \mathrm{mo})\end{array}$ & $\begin{array}{l}+(3 \mathrm{mo}) \\
+(10 \mathrm{mo})\end{array}$ & $\begin{array}{l} \pm(7 \mathrm{mo}) \\
\pm(12 \mathrm{mo})\end{array}$ & $\begin{array}{l}+(3 \mathrm{mo}) \\
+(15 \mathrm{mo})\end{array}$ \\
\hline standing & - & - & $+(18 \mathrm{mo})$ & $+(2 y r)$ & $+(3 y r)$ & - & - & - & $+(20 \mathrm{mo})$ & $+(20 \mathrm{mo})$ & - & $+(17 \mathrm{mo})$ \\
\hline walking & - & - & $+(2 \mathrm{yr})$ & $+(8 \mathrm{yr})$ & $+(4 \mathrm{yr})$ & - & - & - & $+(2 \mathrm{yr})$ & $\pm(2 \mathrm{yr})$ & - & $+(18 \mathrm{mo})$ \\
\hline running & - & - & $\pm(7 \mathrm{yr})$ & - & - & - & - & - & - & - & - & - \\
\hline $\begin{array}{l}\text { Strabismus } \\
\text { Muscle strength }\end{array}$ & - & - & - & - & - & + & - & - & + & - & - & - \\
\hline upper limbs & -2 & -2 & normal & -1 & -1 & -2 & -2 & -2 & -1 & -1 & -2 & -2 \\
\hline lower limbs & -3 & $-\overline{3}$ & -1 & -2 & -2 & -3 & -3 & -3 & -1 & -2 & -3 & -2 \\
\hline Muscle tone $^{00}$ & -3 & -2 & -1 & $-\overline{2}$ & $-\overline{1}$ & -2 & -2 & -2 & -1 & -1 & -2 & -2 \\
\hline Muscle trophism ${ }^{00}$ & -3 & -2 & normal & -1 & -1 & -2 & -2 & -2 & -1 & -1 & -2 & -2 \\
\hline Tendon reflexes ${ }^{00}$ & & & & & & & & & & & & \\
\hline $\begin{array}{l}\text { upper limbs } \\
\text { lower limbs }\end{array}$ & $\begin{array}{l}-3 \\
-3\end{array}$ & $\begin{array}{l}-3 \\
-3\end{array}$ & $\begin{array}{l}-2 \\
-3\end{array}$ & $\begin{array}{l}-1 \\
-1\end{array}$ & $\begin{array}{l}-3 \\
-3\end{array}$ & $\begin{array}{l}-3 \\
-3\end{array}$ & $\begin{array}{l}-3 \\
-3\end{array}$ & $\begin{array}{l}-3 \\
-3\end{array}$ & $\begin{array}{l}-3 \\
-3\end{array}$ & $\begin{array}{l}-3 \\
-3\end{array}$ & $\begin{array}{l}-3 \\
-3\end{array}$ & $\begin{array}{l}-2 \\
-3\end{array}$ \\
\hline
\end{tabular}

*The number indicates how many joints are involved. ${ }^{\circ}$ Absent $(-)$, partial $(+)$ or full acquisition $(+)$ of each motor milestone is indicated; age of acquisition in brackets. ${ }^{\star \star}$ Both cases 6 and 9 showed paralysis of the right Lateral Rectus. ${ }^{\circ}$ Mild $(-1)$, moderate $(-2)$ or severe $(-3)$ decrease of muscle functions is shown.

also recorded on all the patients. If not performed previously, cerebral computerised tomography (CT) was carried out at the time of the last clinical control.

Necropsy neuropathological examination was performed in case 8.

\section{Results}

During our study none of the patients showed signs of pyramidal tract involvement: previously, in case 6 deep tendon reflexes at lower limbs were brisk at four months of age, but after two years the same reflexes were decreased as in all the other patients. In the same case, as in the others, plantar reflexes were flexor and muscle tone decreased.

Clinical evaluation and general intelligence tests indicated a normal intellectual ability in case 1 (Raven Progressive Matrices 38: score 42, level III-), case 2 (Stanford Binet: IQ 105), case 5 (Stanford Binet: IQ 98), case 8 (Stanford Binet: IQ 102), case 10 (Stanford Binet: IQ 113), case 11 (Stanford Binet: IQ 106) and case 12 (Raven Progressive Matrices 47: score 29, level III +). At the time of our study, cases $2,6,10$ and 11 were under age for entrance to the elementary school. Case 1, who had already finished junior high school, and cases 5 and 12, who were in regular elementary school, did not have a history of learning difficulties. As summarised in table 2, there was evidence of mental retardation in the remaining five cases $(42 \%)$.
In case 3, a 10 year old girl, it appeared to a mild degree with a total IQ score of 69 on WISC (verbal IQ: 67; performance IQ: 76) and 67 on the Stanford Binet. She was in the third grade of her elementary school and was helped by a special teacher because of her poor learning abilities. A mild mental retardation was also found in case 4, an 11 year old girl with a total IQ score of 75 on the WISC (verbal IQ: 75; performance IQ: 80 ) and 69 at the Stanford Binet. She was in a special fourth grade class of the elementary school because of her learning problems and motor difficulties.

Clinical evaluation of cases 6 and 7, homozygous twin sisters, indicated the presence of a severe form of mental retardation: at six years of age they were just beginning their toilet training and were only able to say three or four words and to understand a few more. It was not possible to carry out the Wechsler Preschool test. Both were also unable to complete the Stanford Binet subtests corresponding to a mental age of two years, suggesting an IQ lower than 32.

Repeated clinical observations of case 9, a six year old girl who had not yet started the primary school because of obvious learning difficulties, indicated a moderate mental retardation. She was able to speak single words at 22 months and was toilet trained by four years. When she was six years she was able to speak three to four word sentences. Her IQ score on the Stanford Binet test was 42. The same patient had epilepsy. Atonic seizures and

Table 2 CNS alterations in the 12 patients with CMD

\begin{tabular}{|c|c|c|c|c|c|c|c|c|c|c|c|c|}
\hline $\begin{array}{l}\text { Case } \\
\text { Age (years, months) } \\
\text { Sex }\end{array}$ & $\begin{array}{l}1 \\
16 \cdot 3 \\
M\end{array}$ & $\begin{array}{l}2 \\
\mathrm{~F}\end{array}$ & $\begin{array}{l}3 \\
10 \cdot 8 \\
\mathrm{~F}\end{array}$ & $\begin{array}{l}4 \\
11 \cdot 8 \\
F\end{array}$ & $\begin{array}{l}5 \\
9 \cdot 3 \\
F^{-3}\end{array}$ & $\stackrel{6}{6}^{6 \cdot 2}$ & $\begin{array}{l}7 \\
6 \cdot 2 \\
F\end{array}$ & $\stackrel{8}{M}^{6^{\star}}$ & $\stackrel{9}{6}^{6} \cdot 4$ & $\begin{array}{l}10 \\
2 \cdot 7\end{array}$ & $\begin{array}{l}11 \\
5 \cdot 4\end{array}$ & $\begin{array}{l}12 \\
\mathbf{M} \cdot 7\end{array}$ \\
\hline $\begin{array}{l}\text { Mental retardation } \\
\text { (Standford Binet, IQ) }\end{array}$ & - & - & $\begin{array}{l}\text { mild } \\
(0 \cdot 67)\end{array}$ & $\begin{array}{l}\text { mild } \\
(0 \cdot 69)\end{array}$ & - & $\begin{array}{l}\text { severe } \\
(<0.32)\end{array}$ & $\begin{array}{l}\text { severe } \\
(<0.32)\end{array}$ & - & $\begin{array}{l}\text { moderate } \\
(0.42)\end{array}$ & - & - & - \\
\hline Epilepsy & - & - & - & - & - & - & - & - & severe & - & - & - \\
\hline EEG alterations & - & - & - & - & - & - & - & - & diffuse & - & - & focal \\
\hline $\begin{array}{l}\text { Brain CI scan } \\
\text { ventricular dilatation }\end{array}$ & mild & - & - & - & - & moderate & moderate & - & severe & mild & moderate & - \\
\hline cerebral atrophy & moderate & - & - & - & - & moderate & moderate & - & - & - & - & - \\
\hline cerebellar atrophy & 一 & - & & mild & & - & - & - & & & & - \\
\hline $\begin{array}{l}\text { white matter } \\
\text { hypodensity }\end{array}$ & moderate & - & moderate & - & moderate & mild & - & moderate & severe & moderate & moderate & - \\
\hline arachnoid cyst & - & - & - & - & cerebellar & - & - & - & - & - & - & - \\
\hline
\end{tabular}

$\star$ Of case 8, a patient who died when six year old, brain necropsy examination was also performed (see fig 3 ).

Each type of alteration is extensively described in the Results. 


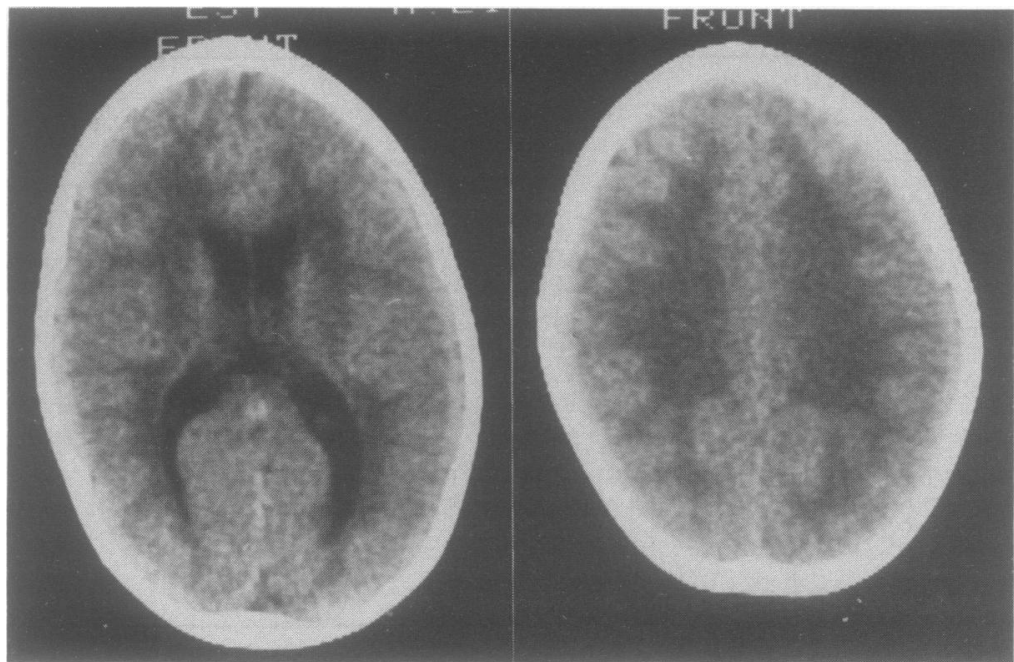

Figure 1 Brain CT scan of case 10, a two year old dystrophic patient without clinical signs or symptoms of CNS involvement: mild dilatation of lateral ventricules (left) associated with moderate hypodensity of white matter (right).

sporadic grand mal attacks started when she was three years and responded well to phenobarbital and carbamazepine therapy. At the same age interictal EEG showed spikes, polyspikes or polyspike-wave complexes in the temporo-occipital right region. Since the age of four years she has had only complex absences, mainly of the atonic type, without consistent benefit from therapy with benzodiazepines, valproic acid, carbamazepine, ethosuximide, phenobarbital, used alone or combined. Two years later atonic absences that occured 20-30 times a day were observed by her parents, while she was being treated with valproate $(25 \mathrm{mg} /$ $\mathrm{kg} /$ day $)$, clonazepam $(0 \cdot 15 \mathrm{mg} / \mathrm{kg} /$ day $)$ and carbamazepine $(20 \mathrm{mg} / \mathrm{kg} /$ day). During these attacks the EEG showed bilateral and synchronous discharges of irregular $3-\mathrm{Hz}$ polyspike-wave complexes or polyspikes. Interictal EEG was characterised by frequent bursts of polyspikes or polyspike-slow wave complexes either bilateral and synchronous or in the posterior regions. Treatment with ACTH (4 $\mathrm{IU} / \mathrm{kg} /$ day) decreased the attacks temporarily.

Case 12, a five year old boy, did not have

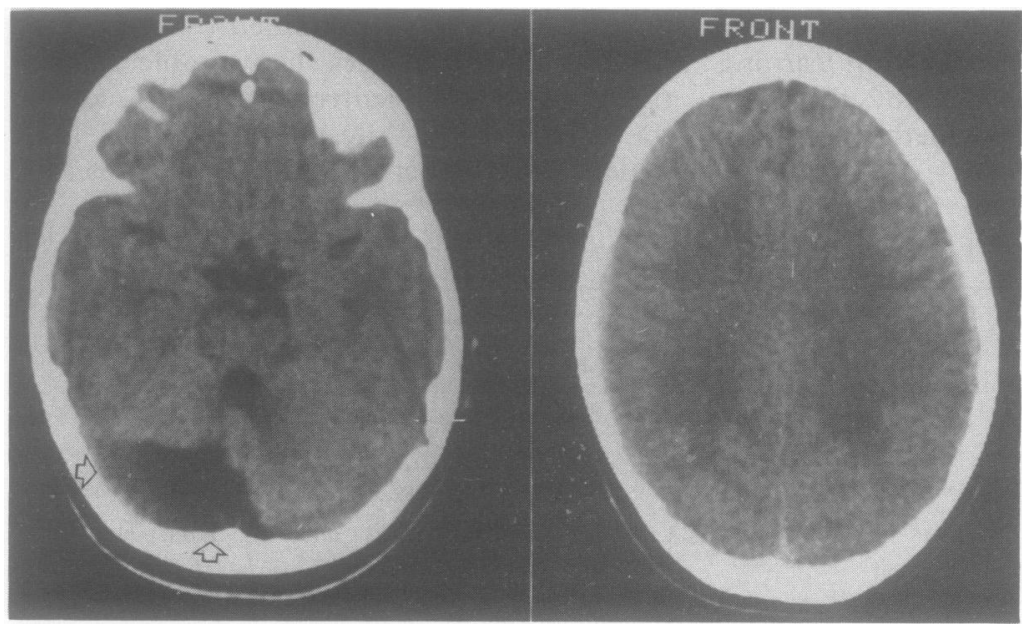

Figure 2 Brain $C T$ scan of case 5 (when aged five years) a patient with $C M D$ and no clinical evidence of brain alterations: arachnoid cyst in posterior fossa (see arrows in the left side) with evident hypodensity of hemispheric white matter( right). epileptic attacks, even though the EEG showed brief paroxismal discharges of spikes or polyspikes in the right parietal region.

Table 2 summarises the neuroradiological alterations found at CT in 10 out of 12 patients with CMD. In five (cases 3, 4, 6, 7, 9) the brain abnormalities were associated with clinical signs of CNS involvement, whereas in another five cases $(1,5,8,10,11)$ the CT scan alterations did not correspond clinically. In six cases $(1,6$, $7,9,10,11)$ there was ventricular enlargement: mild in case 1 and 10 (fig 1), moderate in case 6 and 7 , severe and mainly occipital in case 9 , and moderate and limited to the fourth ventricle in case 11. Ventricular dilatation was associated in three cases $(1,6,7)$ with moderate cortical atrophy. In eight patients (cases $1,3,5,6,8-11$ ) there was diffuse white matter hypodensity in the supratentorial areas, mild in case 6, moderate (fig 1,2 ) in cases $1,3,5,8,10,11$ severe in case 9 . In case 5 (fig 2), a wide arachnoid cyst in the right side of the posterior fossa was also evident. Finally, in case 4 CT scan showed a mild cerebellar atrophy. The degree of CNS involvement did not correlate with the severity of the muscular deficit nor to the extent of the CPK alteration.

Necropsy brain examination was performed on case 8 , whose CT scan previously showed a diffuse white matter hypodensity without clinical symptoms or signs of CNS involvement. The skull presented a left temporo-parietal fracture; an epidural acute haematoma covered the left temporal cerebral area. The brain weighed $1480 \mathrm{~g}$, the cerebral surface was moderately polygyric in the frontal regions and clearly pachygyric in the poles and in the inferior faces of the occipital lobes (fig 3A). On cut surfaces, the pachygyric occipital lobes presented a thickened cortex with small grey heterotopic areas in the white matter (fig 3B).

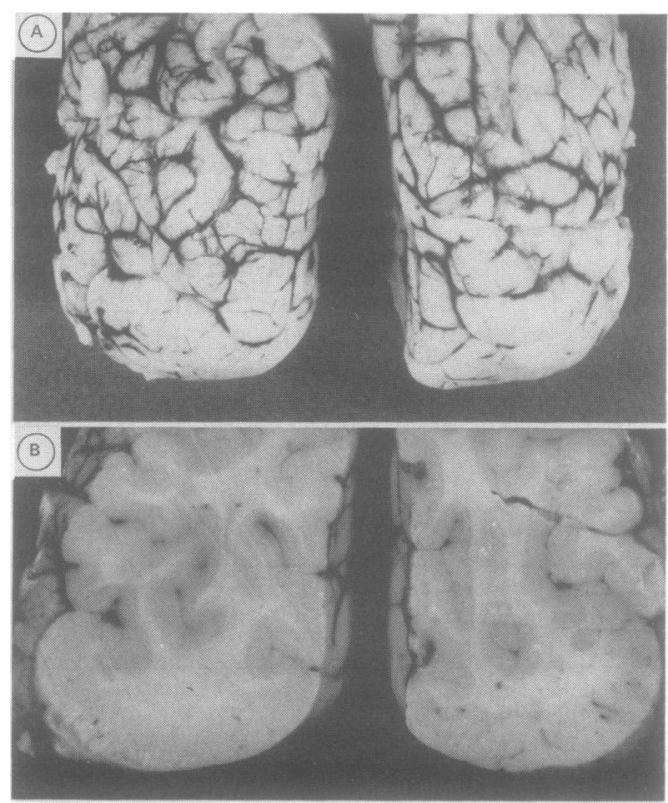

Figure 3A, B Brain of case 8. This patient had had no CNS clinical abnormality but moderate hypodensity of white matter at CT scan: evident pachygyria at surface view of the occipital poles (fig $3 A$ ). At coronal section, the pachygyric occipital lobes show a pale thickened cortex and, less evident underneath, some small areas of heterotropic grey matter (fig $3 B$ ). 
On microscopic examination of the occipital lobes there was evidence of pachygyric cortex with a disorganised cytoarchitectonic and some heterotopic neuronal groups. In the white matter, laminar areas of demyelination, sometimes of confluent type, were detected.

\section{Discussion}

CMD is a rare myopathy essentially characterised by neonatal muscular weakness and hypotonia, associated with changes of dystrophic type at muscle biopsy. ${ }^{1-5}$ This congenital disease is apparently transmitted as an autosomal recessive trait; however, suggestions for an inflammatory process occurring in utero have been reported in cases with CNS involvement. ${ }^{30-34}$ Arthrogryposis congenita, as in our cases, is often an accompanying feature of the disease. Variable elevation of plasma CPK and myopathic alterations at electromyography are other characteristics, even if not essential signs of the disease.

As in our series, the muscular deficit may range from mild to severe, as pointed out by Donner et $a l,,^{35}$ and the clinical course tends to remain relatively static after the first year of age, with a variable improvement of motor abilities afterwards. ${ }^{1-535}$ In some patients, as particularly evident in the series of McMenamin et $a l,{ }^{36}$ the muscular deficit appears progressive, with death in childhood or late adolescence. Nonetheless, in Western countries separating CMD into benign and severe forms is generally considered arbitrary since definite distinguishing criteria are lacking. ${ }^{1-5} 35$

Conversely, a severe muscular deficit with progression to death at the mean age of eight to 10 years appears as a constant feature of the Japanese variant of CMD (FCMD), as described by Fukuyama et al in $1960 .^{7}$ This form of CMD is also characterised by mental retardation, usually of moderate to severe degree, ${ }^{89}$ combined in about $50 \%$ of patients with seizures and abnormal EEG. ${ }^{2}$ Brain CT scan altered in up to $90 \%$ of cases. ${ }^{8}{ }^{10}$ As reviewed by Nonaka and $\mathrm{Chou},{ }^{2}$ and Yoshioka et al, ${ }^{8}$ the common neuropathological findings at necropsy of patients with FCMD, were symmetrical focal gyral anomalies, such as agyria pachygyria and micropolygyria, mainly in temporal and occipital lobes. High pressure hydrocephalus, abnormal fusion of hemispheres at the frontal lobes and other anomalies were also occasionally found in the same type of CMD.

In the typical CMD of Western countries, clinical manifestations of CNS involvement are considered characteristically absent, ${ }^{2-5}$ even though occasionally reported. ${ }^{11-29}$ When detected, signs of CNS alterations were rather variable. In some patients, as in three of our cases, the presence of clearcut mental retardation often associated with epilepsy, is reminiscent of CNS involvement characteristic of FCMD. ${ }^{22-27}$ Furthermore, necropsy neuropathological examination showed the gyral anomalies characteristic of FCMD also in some Occidental patients. ${ }^{11} 12227$ In the cases described by Santavuori et $a l^{13-15}$ and in other reports, ${ }^{17182526}$ mental retardation and epilepsy were associated with ocular abnormalities and high pressure hydrocephalus, alterations less rarely seen in FCMD. ${ }^{89}$

In other Western patients, as in two of our cases who had mild mental retardation, the clinical manifestations of CNS involvement were less striking than those usually found in FCMD. ${ }^{1213577}$ In some Japanese children, however, the brain alteration may be mild, ${ }^{89}$ as reviewed by Nonaka and $\mathrm{Chou}^{2}$ and confirmed in a case of ours and in one of the cases of Bernier et al. ${ }^{16}$ EEG abnormalities were detected in the absence of clinical evidence of epilepsy or other brain alterations in some patients with typical CMD.

Some authors ${ }^{16} 19202127$ reported Western patients affected by CMD who did not present with symptoms or signs of CNS involvement, but like five of our patients, only abnormalities at CT scan. As in Japanese children, ${ }^{810}$ the neuroradiological alterations were mainly characterised by white matter hypodensity and cerebral atrophy, or less frequently, by hydrocephalus or cerebellar cysts. Decreased density of the cerebral white matter has been questioned as a reliable indication of brain disease in children. ${ }^{5}$ However, in a patient of ours who did not present with any other indication of CNS involvement, the necropsy neuropathological examination showed gyral anomalies characteristic of FCMD, even though less striking than those found in Japanese patients. ${ }^{238}$ This confirmed the indication derived from the neuroradiological study, that some CNS involvement may be present in typical CMD even when the patients do not suffer from epilepsy or mental retardation.

Taken together, data from reported cases ${ }^{11-28}$ and from our series of patients indicate that Western patients with CMD may have variable CNS alterations ranging from a subclinical degree $^{216192127}$ to a severe one, similar to that characteristic of FCMD. ${ }^{22-27}$ So far as a subclinical brain involvement is concerned, dystrophic patients who do not suffer from disturbances related to CNS alterations show neuroradiological abnormalities similar to, but milder than those presented by Japanese children with FCMD. ${ }^{8-10}$ In contrast with the general opinion that brain alterations are rare in the Occidental form of $\mathrm{CMD}^{2-5}$ our CNS study of an unselected series of Western patients with CMD indicates that some degree of neuroradiological CNS involvement is present in the vast majority of children with typical CMD. Quantitatively, however, our data on frequency of neuroradiological alterations in Occidental CMD cannot be compared with previous reports, since these described selected patients. ${ }^{11-28}$

The typical Western CMD appears as a myoencephalopathy similar to the Japanese form. The two forms seem distinguishable not only by the absence or presence of CNS pathology, as generally accepted, ${ }^{2-5}$ but also by the severity of the pathological process: this usually appears most marked in the Japanese and subclinical in the Western patients. Finally, evidence of clearcut mental retardation 
with epilepsy in a patient of our series (case 9) and only neuroradiological CNS alterations in her sister (case 10), corroborates the hypothesis that the distinction of different CMD formed merely on the basis of clinical manifestations of CNS involvement ${ }^{21-27}$ could be arbitrary.

This paper was presented at the XIVth World Congress of Neurology (New Delhi, India) in October 1989."

The work was supported in part by "Legato Dino Ferrari" and Italian CNR grants.

We are grateful to Dr F Devetag for referring and helping with two patients.

1 Vassella F, Mumenthaler M, Rossi E, et al. Die Kongenitale Muskeldystrophie. Deut $Z$ Nervenheilk 1967;190:349-74. Nonaka I, Chou SM. Congenital muscular dystrophy. In: Vinken PJ, Bruyn GW, eds. Handbook of clinical neurology. Amsterdam: North-Holland Publishing, 1979 41:27-50

3 Dubowitz V. The floppy infant. London: Spastic International Medical Publications, 1980:77-86.

4 Fardeau M. Congenital myopathies. In Mastaglia FL, Walton J, eds. Skeletal muscle pathology. Edinburgh: Churchill-Livingstone, 1982:161-203.

5 Banker B. Congenital muscular dystrophy. In: Engel G Banker B, eds. Myology. New York: McGraw-Hill, 1986: 1367-82.

6 Howard R. A case of congenital defect of the muscular system (Dystrophia Muscularis Congenita) and its association with congenital talipes equino-varus. Proc Roy association with congenital
Soc Med 1908;1:157-66.

7 Fukuyama Y, Kawazura $M$, Haruna M. A peculiar form of congenital progressive muscular dystrophy. Report of fifteen cases. Paediat Univ Tokyo 1960;4:5-8.

8 Yoshioka M, Okuno T, Honda W, et al. Central nervous system involvement in progressive muscular dystrophy. Arch Dis Child 1980;55:589-94.

9 Fukuyama Y, Osawa M, Suzuky H. Congenital progressive dystrophy of the Fukuyama type-clinical, genetic and pathological considerations. Brain Dev 1981;3:1-29.

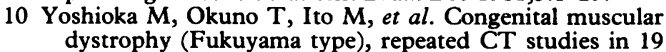
children. Comp Tomogr 1981;5:81-88.

11 Jervis GA. Progressive muscular dystrophy with extensive demyelination of

12 Fowler M, Manson SI Congenital muscular dystrophy with malformations of the central nervous system. In: Kakulas BA, ed. Clinical studies in myology. Amsterdam: Excerpta BA, ed. Clinical studica, 1973:192-7.

13 Santavuori P, Leisti J, Kruus J. Muscle, eye and brain disease. A new syndrome. Neuropaediatrie 1977;8:550-3.

14 Santavuori P, Leisti J, Kruus J, et al. Muscle, eye and brain disease. A new syndrome. Docum Ophthalmol Proc $S$ 1978;17:393-6.

15 Raitta C, Lamminen M, Santavuori P, et al. Ophthalmological findings in a new syndrome with muscle, eye and brain involvement. Acta Ophthalmol 1978;56:465-72.

16 Bernier SP, Brooke MH, Naidich TP, et al. Myoencephalopathy: cerebral hypomyelination revealed by CT scan of the head in a muscle disease. Trans Amer Neurol Ass 1979;104:244-6.

17 Krijgsman JB, Barth PG, Stam FC, et al. Congenital muscular dystrophy and cerebral dysgenesis in a Dutch family. Neuropaediatrie 1980;11:108-20.

18 Dambska M, Wisniewski K, Sher S, et al. Cerebro-oculo- muscular syndrome: a variant of Fukuyama congenital cerebromuscular dystrophy. Clin Neuropathol 1982;1: 93-9.

19 Nogen AG. Congenital muscle disease and abnormal findings on computerized tomography. Dev Med Child Neurol ings on compute $1980 ; 22: 658-63$.

20 Gobernado JM, Gimemo A. Changes in cerebral white matter in 2 cases of congenital muscular dystrophy. Pediatr Radiol 1982;12:201-3.

21 Egger J, Kendall BE, Erdohazi M, et al. Involvement of the central nervous system in congenital muscular dystrophies. Develop Med Child Neurol 1983;25:32-42.

22 Goebel HH, Fidzianska A, Lenard HG, et al. A morphological study of non-Japanese congenital muscular dystrophy associated with cerebral lesions. Brain Dev 1983;5:292-301.

23 Vles JSH, Dekram MCT, Visser R, et al. Two Dutch siblings with congenital muscular dystrophy (Fukuyama type). Clin Neurol Neurosurg 1983;85-3:175-80.

24 Peters ACB, Bots GTA, Roos RAC, et al. Fukuyama type congenital muscular dystrophy in two Dutch siblings. Congenital muscular dystrop

25 Korinthemberg R, Palm D, Schlake W, et al. Congenital muscular dystrophy, brain malformation and ocular problems (muscle, eye and brain disease) in two German families. Europ J Pediatr 1984;141:64-68.

26 Towfighi J, Sassani JW, Suzuki K, et al. Cerebro-Ocular Dysplasia-Muscular Dystrophy (COD-MD) Syndrome. Acta Neuropathol 1984;65:110-23.

27 Echenne B, Arthuis M, Billard C, et al. Congenital muscular dystrophy and cerebral CT scan anomalies. Results of a collaborative study of the Société de Neurologie Infantile. J Neurol Sci 1986;75:7-22.

28 Martinelli P, Gabellini AS, Giucci G, et al. Congenital muscular dystrophy with central nervous system involvement: Case report. Eur Neurol 1987;26:17-22.

29 Trevisan CP, Carollo C, Massocchi P, et al. Central nervous system involvement in congenital muscular dystrophy. Acta Neurol NS 1984;6:364.

30 Hansson O, Kristenssen K, Lycke E, et al. Generalized myopathy and cerebral malformation possibly related to an enteroviral infection. Acta Pediatr Scand 1975;64: 881-5.

31 Miyake S, Goto A, Tsuchida M, et al. An autopsy case of congenital muscular dystrophy associated with hydrocephalus and occipital dermal sinus. Brain Dev 1977;9: 212-19.

32 Saito K, Fukuyama Y, Ogata T, et al. Experimental intrauterine infection of Akabane virus. Pathological studies of skeletal muscles and central nervous system of newborn hamsters with relevance to the Fukuyama type newborn hamsters with relevance to the Fukuyama type
congenital muscular dystrophy. Brain Dev 1981;3:65-80.

33 Olney RK, Miller RG. Inflammatory infiltration in Fukuyama type congenital muscular dystrophy. Muscle Nerve 1983;6:75-76.

34 Tatsuno $M$, Iwamoto $H$, Misugi $N$. A case of intrauterine infection with myopathy. Brain Dev 1983;5:207.

35 Donner M, Rapola J, Somer H. Congenital muscular dystrophy: a clinico-pathological and follow-up study of 15 patients. Neuropaediatrie 1975;6:239-61.

36 Mac Menamin JB, Becker LE, Murphy EG. Congenital muscular dystrophy. A clinico-pathologic report of 24 cases. J Pediatr 1982;100:692-7.

37 Zellweger H, Afifi A, McCormick WF, et al. Severe congenital muscular dystrophy. Amer $J$ Dis Child 1967; 114:591-602.

38 Kamoscita S, Konishi Y, Segawa M, et al. Congenital muscular dystrophy as a disease of the central nervous system. Arch Neurol 1976;33:513-16.

39 Trevisan CP, Segalla P, Angelini C, et al. Alterations of central nervous system in the occidental form of 37(Suppl 1):511D02. 